\title{
Diagnóstico tardío de sarcoma de talón
}

Late diagnosis of heel sarcoma

Úrsula Ponce Villar ${ }^{1}$

ORCID https://orcid.org/0000-0002-4458-922X

Fabián Peiró Monzó

ORCID https://orcid.org/0000-0002-4380-1479

Jesús Seguí Gregori ${ }^{2}$

ORCID https://orcid.org/0000-0001-5456-0538

DOI 10.31837/cir.urug/5.1.3

Recibido: 17 de abril de 2020

Aceptado: 23 de julio de 2020



Fig. 1

${ }^{1}$ Facultativo Especialista Adjunto de Cirugía General y del Aparato Digestivo. Hospital Francesc de Borja, Gandía, Valencia., España. ursulapv85@hotmail.com

${ }^{2}$ Jefe de servicio Cirugía General y del Aparato Digestivo.Hospital Francesc de Borja, Gandía, Valencia, España 
Mujer 39 años, consultó por talalgia desde hacía un año, con radiografía anodina. A los 5 meses presentó tumoración en talón abscesificada (Fig.1), y se realizó drenaje y biopsia de la tumoración que informó de sarcoma fusocelular de alto grado. Se completó estudio con resonancia que describió tumoración excrecente de $5 \mathrm{~cm}$ contactando con calcáneo y fascia plantar (Fig.2: flechas amarillas).

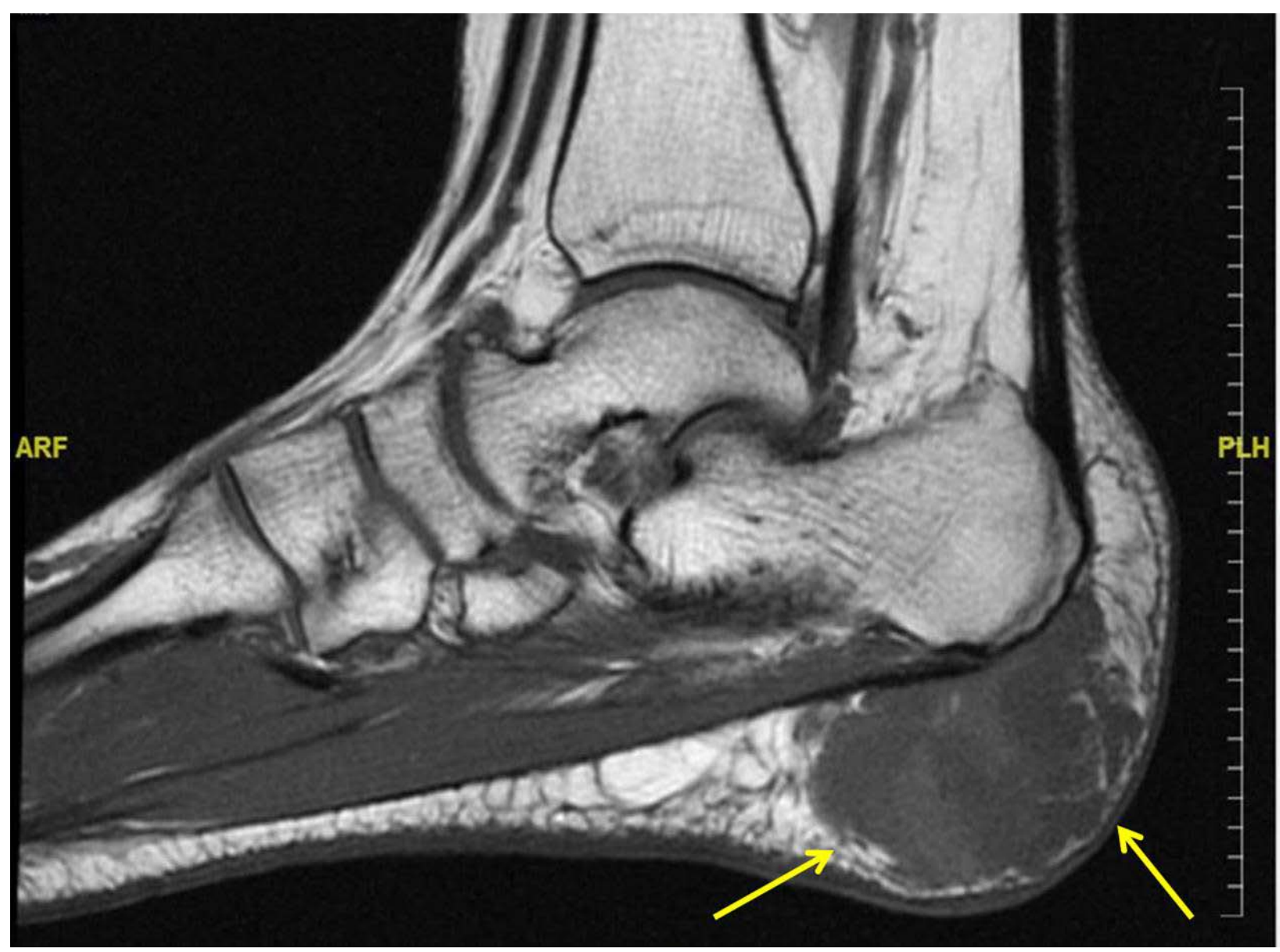

Fig. 2

Quedó pendiente de iniciar quimioterapia. Al mes, cursó con tos y hemoptisis, y la tomografía torácica evidenció metástasis pulmonares bilaterales con gran tumoración en lóbulo superior derecho (Fig.3: flechas amarillas). 


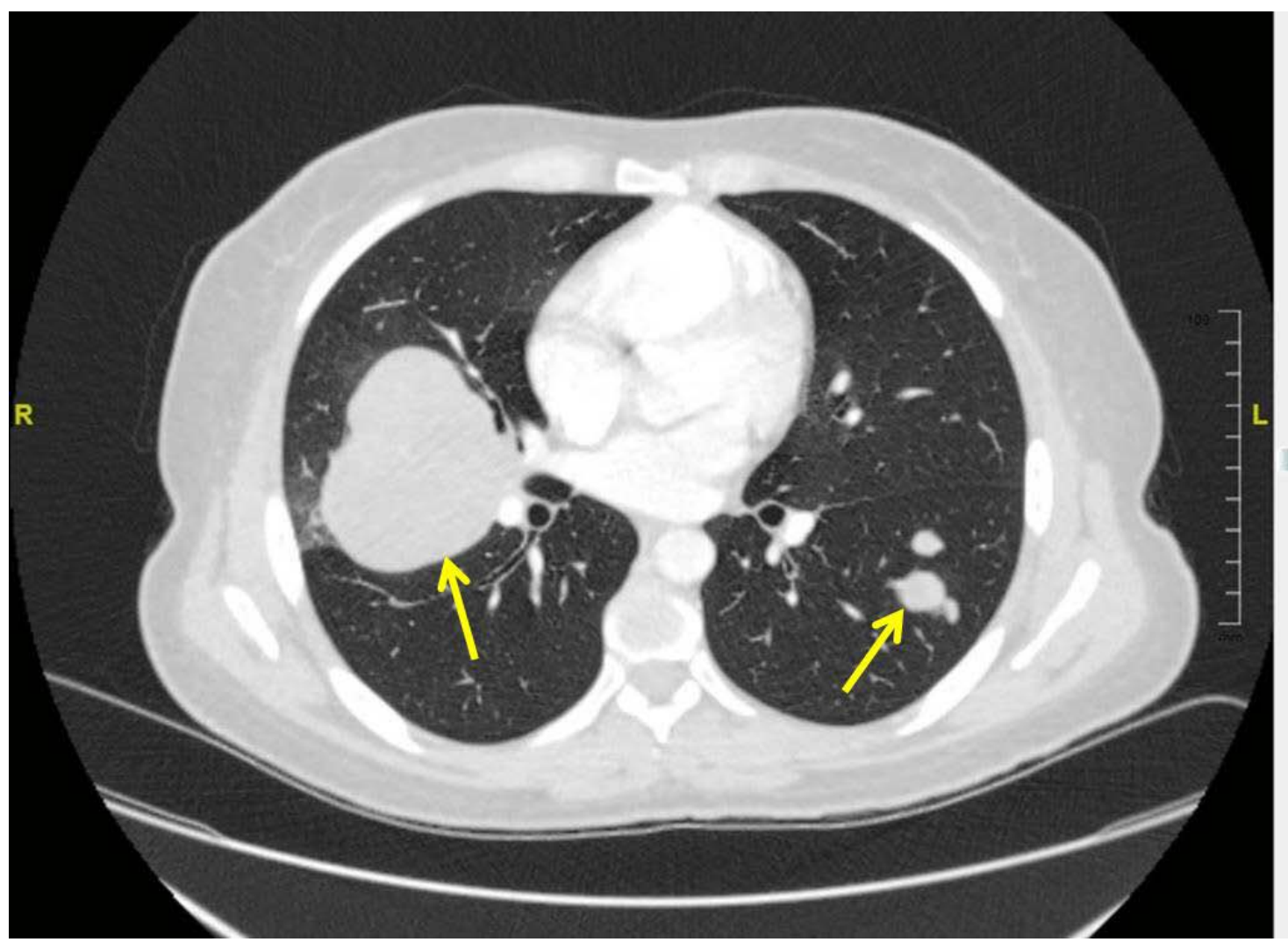

Fig. 3

A los 15 días,presentóabdomen agudo,interviniéndose de urgenciaencontrando perforación yeyunal por implante tumoral con carcinomatosis peritoneal y metástasis hepáticas múltiples. Se realizó resección segmentariade yeyuno con anastomosis, siendo dada de alta y éxitus al mes por evolución de la enfermedad.

Los sarcomas presentan unarápida progresión condesarrollo de metástasis. El diagnóstico precoz de estos tumores es vital para mejorar el pronóstico. 